\title{
Obestatin/Ghrelin Ratio as a New Activity Index in Ulcerative Colitis
}

\author{
"Mohammed Amin Mohammed ${ }^{1}$, Nesreen Moustafa Omar ${ }^{2}$ \\ ${ }^{1}$ Department of Internal Medicine, Hepatology, Gastroenterology, and Endoscopy Unit, Faculty of Medicine, \\ Mansoura University, Egypt \\ ${ }^{2}$ Department of Histology and Cell Biology, Faculty of Medicine, Mansoura University, Egypt
}

"Correspondence Author: Mohammed Amin Mohammed, MD, Assistant Professor, Department of Internal Medicine, Hepatology, Gastroenterology, and Endoscopy Unit, Faculty of Medicine, Mansoura University, Egypt; liver2345@gmail.com, ORCID: http://orcid.org/0000-0003-3023-3094

Received 27 March 2019;

Accepted 13 April 2019;

Published 20 April 2019

\begin{abstract}
Background and Aim: Ulcerative colitis (UC) is an immune-mediated systemic inflammatory process that destroys the intestinal mucosa. Ghrelin, an appetite-regulatory hormone, has anti-inflammatory effects including a decrease in circulating cytokines. Some reports demonstrated a strong relationship between the serum ghrelin level and the severity of mucosal inflammation in the gastrointestinal tract. The aim is to investigate serum levels and colonic mucosal mRNA expression of ghrelin, obestatin, and obestatin/ghrelin ratio in patients with UC and to determine their potential as markers for UC disease activity. Patients and Methods: seventy-five outpatients with UC and 45 age- and sexmatched healthy volunteers were enrolled in this study after written conscious consent and approval by the Institutional Review Board of Mansoura University. UC was diagnosed by conventional clinical, radiological, endoscopic, and histopathological criteria. Serum ghrelin, obestatin levels, and their mucosal mRNA expression were measured by ELISA kits and a real-time quantitative reverse transcriptase polymerase chain reaction according to the manufacturer's protocols. Results: Serum levels and mucosal mRNA expression of ghrelin were significantly higher in patients with active UC than patients in remission $(\mathrm{p}<0.0001)$. Obestatin/ghrelin ratio was significantly lower in patients with active UC $(0.26 \pm 0.08)$ than those in remission $(0.523 \pm 0.16 ; p<0.0001)$. Obestatin/ghrelin ratio was negatively and significantly correlated with inflammation and endoscopic scores, colitis activity index, serum ghrelin level, and its mucosal mRNA expression $(\mathrm{p}<0.05)$. Conclusion: obestatin/ghrelin ratio might be a reliable surrogate non-invasive marker of disease activity in UC with significantly high sensitivity, specificity, predictive values, and diagnostic accuracy.
\end{abstract}

Keywords: Ghrelin, Obestatin/ghrelin ratio; Ulcerative Colitis; inflammatory bowel disease

\section{Introduction}

Ulcerative colitis (UC) is an immune-mediated systemic inflammatory process that destroys the intestinal mucosa. ${ }^{[1]}$ Although genetic, infectious, and immunological factors may play roles in inflammatory bowel disease (IBD), the etiology remains idiopathic. ${ }^{[2]}$ IBD is associated with alterations in visceral fat mass and fat distribution. Submucosal fat deposition (fat halo sign) is found in patients with IBD. ${ }^{[3]}$ Moreover, crohn's disease (CD) is characterized by intra-abdominal fat accumulations and mesenteric adipose tissue hypertrophy. ${ }^{[4]}$

Ghrelin, a 28-amino acid peptide, is an anabolic and appetiteregulatory hormone produced mainly by enteroendocrine cells of the gastric mucosa situated mainly in the corpus and fundus of the stomach. ${ }^{[5]}$ ghrelin, to a lesser extent, was found to be expressed in and secreted from multiple tissues like the gut, kidney, lung, pancreas (A cells) and hypothalamic nucleus. ${ }^{[6]}$ Plasma ghrelin secretion is episodic and dimorphic. Only the active acylated (octanoylated) form of ghrelin plays central as well as peripheral roles in energy metabolism by stimulating growth hormone secretion in the pituitary. ${ }^{[7]}$ Also, it promotes adipogenesis in the adipose tissue through its action on energy-regulating centers in the hypothalamus. ${ }^{[8]}$ Furthermore, ghrelin acts on lymphocyte receptors to provide anti-inflammatory effects, including a decrease in circulating cytokines. ${ }^{[9]}$ Ghrelin is considered to be a short-term orexigen related to meals as its plasma concentrations rise before and decrease after meals. Collectively, ghrelin regulates somatic and adipose tissue growth thus contributes to long term regulation of body weight. ${ }^{[10]}$ Some reports demonstrated a strong relationship between the serum ghrelin level and the severity of mucosal inflammation in the gastrointestinal tract. ${ }^{[11]}$ 
It has been hypothesized that chronic gastritis and gastric damage with or without atrophy affect gastric ghrelin mRNA expression and consequently plasma ghrelin level because of the gastric location of ghrelin producing cells. A previous study reported lower serum ghrelin levels, gastric ghrelin mRNA expression that correlated with the $\mathrm{H}$ pylori infection, topographic distribution of gastric glandular atrophy, and histological glandular atrophy scores. In that study, the attenuation of the ghrelin mRNA expression and consequently reduced ghrelin production in the gastric mucosa may account for the decrease in the serum ghrelin levels. ${ }^{[12]}$ Another study showed increased ghrelin levels irrespective to the severity of duodenal inflammation in patients with celiac disease. ${ }^{[13]}$ Also, it reported that ghrelin levels were reduced after gluten-free diet treatment in patients with celiac disease. ${ }^{[14]}$

Obestatin, a 23-amino acid peptide, is an anorectic hormone, produced in specialized epithelial cells of the stomach, encoded by the same gene that encodes ghrelin and opposes the actions of ghrelin decreasing food intake and reducing body weight gain. ${ }^{[15]}$ It is also not surprising that chronic gastritis can also affect gastric obestatin production. ${ }^{[16]}$

Determining inflammatory activity is crucial for assessing the disease activity and for tailoring therapy. It has been suggested that the obestatin/ghrelin ratio could serve as a marker of IBD activity. Few studies measured both the serum ghrelin levels and colonic mucosal ghrelin mRNA expression in the patients with UC. Moreover, no studies have yet evaluated the relationship between obestatin/ghrelin ratio and UC disease activity especially in Egyptian patients. So, the aim of this study is to investigate serum levels and colonic mucosal mRNA expression of ghrelin, obestatin, and obestatin/ghrelin ratio in Egyptian patients with UC, to determine their potentials as markers for disease activity and to assess their predictive values for UC disease activity and severity.

\section{Patients and Methods}

Patients: A total of 75 adult consecutive outpatients older than 18 years, with a confirmed diagnosis of UC were enrolled in this study from July 2017 through 2018. Another 45 healthy subjects (volunteers, medical students, and health workers) without any signs of inflammation or intestinal symptoms matched to the cases by age, sex, and body mass indices (BMI) were also enrolled as a control group. All patients were selected from the outpatient's clinic of IBD in the gastroenterology department of Mansoura University Hospital. A written informed conscious consent was obtained from all participants before their participation. The study was conducted in accordance with the Declaration of Helsinki and Good Clinical Practice Guidelines and was approved by the Institutional Review Board of Mansoura Faculty of Medicine (MFM-IRB; R.18.03.83).

Exclusion criteria: Patients with incomplete ileocolonoscopy, past history of any malignant condition and major gastrointestinal surgical procedures, liver cell failure, coagulopathy, chronic renal failure, congestive heart failure, malignant hypertension or strokes, endocrinal diseases (diabetes, adrenal insufficiency, thyroid disease), cardiopulmonary diseases, advanced chronic or psychiatric illness, pregnancy, smokers, drug or alcohol abuse, Non Steroidal Anti-Inflammatory Drugs (NSAIDs), aspirin intake and any special type of dieting or treatments for the previous 6 months were excluded from the study. Five patients were excluded and the remaining participants underwent routine laboratory and radiological investigations and gastrointestinal endoscopic evaluation at enrollment.

Initially, all participants completed a detailed questionnaire regarding diet and habits, submitted to thorough history taking with special emphasis on abdominal pain, weight loss, rectal bleeding, diarrhea, constipation, malaise, lethargy, anorexia, nausea, tenesmus, abdominal distension, passage of mucus, vomiting and low-grade fever along with detailed physical examinations performed at fasting in the morning.

Methods: at the day of study inclusion, height and weight were measured. BMI was calculated as weight in kilograms divided by height squared in meters $(\mathrm{kg} \mathrm{m}-2)$. The appetites of all subjects were estimated using a Visual Analog Scale (VAS) of appetite. ${ }^{[17]}$ Venous blood samples were obtained from each subject after a minimum of $10 \mathrm{~h}$ of fasting. Serum tubes were centrifuged at $1500 \mathrm{~g}$ for $10 \mathrm{~min}$ at $4^{\circ} \mathrm{C}$, followed by a second centrifugation at $2000 \mathrm{~g}$ for $3 \mathrm{~min}$ at $4^{\circ} \mathrm{C}$, aliquoted and stored at $-80^{\circ} \mathrm{C}$ until assayed. White blood cell (WBC) count, hemoglobin, hematocrit, platelet count, total protein, albumin, cholesterol, triglycerides, erythrocyte sedimentation rate (ESR) and C-reactive protein (CRP) were tested.

The diagnosis of UC was established by clinical, radiological, endoscopic, and histopathological criteria. Clinical disease activity of UC patients was determined according to the colitis activity index (CAI) of Rachmilewitz. ${ }^{[18]}$

Endoscopy: Total colonoscopy and ileoscopy (distal ileum) (colonoscope; XQ40, Pentax Fiberoptic, Tokyo) performed after overnight fast and/or cleansing enemas between 08:00 and 10:00 am. The macroscopic endoscopic features of mucosa were evaluated and multiple biopsies were taken from colon or ileum (from both diseased and healthy areas) for histopathological examination and RNA isolation. The macroscopic endoscopic signs of inflammation were recorded by an experienced gastroenterologist using the Rachmilewitz endoscopic score for ulcerative colitis. ${ }^{[19]}$

The biopsy specimens taken were embedded in Paraffin blocks, sectioned and stained with hematoxylin and eosin for conventional histopathological examination. Biopsy sections were encoded and analyzed semiquantitatively on a four-point scale $(0,1,2,3$; non, mild, moderate and severe inflammation, respectively) by two independent well-trained histopathologists, who were blinded to the endoscopic diagnosis, clinical data, the treatment and subject group identity. This histological inflammation score served as the reference standard to determine the inactive or active UC in this study cohort. UC was considered inactive if there were no histological signs of inflammation (inflammation score <1), an endoscopic score $<4$ and a clinical colitis activity index (CAI) score $<6^{[20]}$

Serum Ghrelin and Obestatin levels were measured by commercially available ELISA kits following the manufacturer's guidelines (Phoenix Pharmaceuticals, INC., Brulingame, CA, USA). For Ghrelin; Catalog\# EK-031-30, detection range: 0-100 $\mathrm{ng} / \mathrm{mL}$ ). For Obestatin; Catalog\# EK-031-90, detection range: $0.231-258 \mathrm{ng} / \mathrm{mL}$ ). The intra-assay and inter-assay coefficient variation were $<10 \%$ and $<15 \%$ respectively for both ghrelin and obestatin. 
The mRNA expression of Ghrelin and Obestatin: Total RNA was extracted and purified from colitis mucosal biopsy specimens with TRIzol $^{\text {TM }}$ Plus RNA Purification Kit (Catalog\# 12183555, Invitrogen Life Technologies, California, USA) using the standard procedure. The mRNA expressions of ghrelin and obestatin were quantified and evaluated by a real-time quantitative reverse transcriptase polymerase chain reaction (qRT-PCR) using the isolated RNA according to the manufacturer's protocol. ${ }^{[21]}$ Realtime qRT-PCR analysis was carried out with SYBR® Premix Ex TaqTM (TaKaRa Bio, Tokyo, Japan, Catalog\# RR041A) and genespecific primers retrieved from Primer Bank. The sequences of primers were as follows: Ghrelin: 5'-ATG CTC CTG TGG GAC TTG-3'(sense) and 5'-TCT GCT TGA CCA CCT TCT T3'(antisense); Obestatin: 5'-AAG ATG GAG GTC AAG CAG AAG-3'(sense) and 5'-GAC AGC TTG ATT CCA ACA TCA$3^{\prime}$ (antisense). The PCR specificity is examined by 3\% Ready Agarose Precast Gel (Bio-Rad). The real-time qRT-PCR results were analyzed with the SDS 7000 software. The gene mRNA levels were corrected using $\beta$-actin.

Statistical analyses were carried out using SPSS version 20.0 software (SPSS Inc, Chicago, IL). Normality of Data was analyzed using the Kolmogorov-Smirnov test. Data were presented as mean \pm SD if normally distributed or median and interquartile range (IQR) if not. Frequencies were used for categorical variables. Comparisons of the characteristics between patients with UC (active and inactive) and healthy controls were performed by T-test for equality of means, Fisher exact test or one-way ANOVA when indicated. The correlations between serum ghrelin and obestatin levels and other parameters were analyzed using Spearman correlation analysis. Receiver Operating Characteristics (ROC) Curves were done. Sensitivity, Specificity, Positive likelihood ratio (PLR), Negative likelihood ratio (NLR), Positive predictive value (PPV), Negative predictive value (NPV), and Diagnostic accuracy were calculated using MEDCALC Software bvba [BE] online; https://www.medcalc.org/calc/diagnostic_test.php. Statistical significance was accepted at a level of $\mathrm{P} \leq 0.05$.

\section{Results}

The demographic, serological, clinical and histological data were shown in Table 1 . This study included 45 healthy controls and 70 UC patients. Forty patients $(58.3 \%$; 19 female and 21 male) had active disease with a mean age 45.4 years (yrs) and the remaining 30 patients $(41.7 \%$; 13 female and 17 male) had inactive UC with a mean age $46.16 \mathrm{yrs}$. The mean duration of disease was $8.89 \mathrm{yr}$ in active UC and $9.12 \mathrm{yr}$ in inactive UC. No significant differences were noticed between healthy controls, active UC and inactive UC as regard age, gender, VAS, BMI, duration of disease, CBC, and s. albumin $(\mathrm{P}>0.05)$. On the other hand, the CRP, ESR, inflammation scores, endoscopic scores and CAI of Rachmilewitz were significantly higher in those with active disease $(p<0.0001)$. Also, Serum levels and mucosal mRNA expression of ghrelin were significantly higher in patients with active UC $(1444 \pm 292.5$, $816 \pm 238.8)$ than those in remission $(735.2 \pm 121.3,616.6 \pm 188.2)$ and healthy controls $(702.7 \pm 132.9,639.8 \pm 213) \quad(\mathrm{p}<0.0001)$. Contrary, obestatin/ ghrelin ratio was significantly lower in patients with active UC $(0.26 \pm 0.08)$ than those in remission $(0.523 \pm 0.16)$ and healthy controls $(0.56 \pm 0.17) \quad(\mathrm{p}<0.0001)$. Although serum obestatin level and its mucosal mRNA expression were lower in active UC compared to inactive disease and healthy controls, their difference didn't reach significance $(\mathrm{p}>0.05)$ (Table 1, Figure 1, 2).

Table 1: Demographic Data, Serological, Clinical, and Histopathological Characteristic Features of all Studied Groups

\begin{tabular}{|c|c|c|c|c|c|c|}
\hline Group (n) & Healthy Controls (45) & Active UC (40) & Inactive UC (30) & $P 1$ & $P 2$ & $P 3$ \\
\hline Gender $(51 ㅇ / \delta 64)$ & $19 / 26$ & $19 / 21$ & $13 / 17$ & .758 & .888 & .897 \\
\hline Age (yrs) & $47.6 \pm 11.27$ & $45.4 \pm 10.8$ & $46.16 \pm 11.9$ & .392 & .622 & .805 \\
\hline VAS & $42.6 \pm 11.7$ & $43.4 \pm 10.3$ & $44.24 \pm 11.7$ & .737 & .566 & .769 \\
\hline BMI $\left(\mathrm{kg} / \mathrm{m}^{2}\right)$ & $23.93 \pm 4.01$ & $19.92 \pm 3.46$ & $21.86 \pm 4.2$ & .0001 & .096 & .024 \\
\hline Duration (yrs) & . & $8.89 \pm 2.3$ & $9.21 \pm 3.3$ & - & - & .696 \\
\hline Hemoglobin (g/dl) & $11.47 \pm 1.22$ & $9.02 \pm 1.16$ & $9.98 \pm 1.4$ & .581 & .978 & .669 \\
\hline Platelets $\left(10^{3} \mathrm{~mm}^{3}\right)$ & $276.4 \pm 34.2$ & $282.5 \pm 37.99$ & $271 \pm 25.4$ & .457 & .486 & .192 \\
\hline WBCs $\left(10^{3} \mathrm{~mm}^{3}\right)$ & $6.74 \pm 1.7$ & $7.6 \pm 1.88$ & $6.98 \pm 1.8$ & .741 & .580 & .439 \\
\hline S. Albumin (g/dl) & $3.95 \pm 0.27$ & $3.18 \pm 0.31$ & $3.29 \pm 0.29$ & .733 & .613 & .870 \\
\hline CRP (mg/dL) & $27.1 \pm 4.92$ & $37.83 \pm 6.18$ & $29.3 \pm 4.9$ & .000 & .547 & .000 \\
\hline ESR & $18.6 \pm 3.78$ & $55.83 \pm 6.18$ & $19.8 \pm 4.06$ & .000 & .206 & .000 \\
\hline Endoscopic score & - & $7.83 \pm 2.57$ & $3.7 \pm 2.3$ & - & - & .000 \\
\hline Inflammation score & - & $2.54 \pm 0.8$ & $0.98 \pm 0.86$ & - & - & .000 \\
\hline CAI & - & $8.11 \pm 1.68$ & $4.96 \pm 1.7$ & - & - & .000 \\
\hline S. ghrelin $(\mathrm{pg} / \mathrm{mL})$ & $702.7 \pm 132.9$ & $1444 \pm 292.5$ & $735.2 \pm 121.3$ & .000 & .316 & .000 \\
\hline mRNA ghrelin & $639.8 \pm 213$ & $816 \pm 238.8$ & $616.6 \pm 188.2$ & .001 & .651 & .001 \\
\hline O/G Ratio & $0.56 \pm 0.17$ & $0.26 \pm 0.08$ & $0.523 \pm 0.16$ & .000 & .318 & .000 \\
\hline S.obestatin $(\mathrm{pg} / \mathrm{mL})$ & $372.3 \pm 86.3$ & $355 \pm 81.33$ & $384.8 \pm 90.85$ & .205 & .735 & .455 \\
\hline mRNA obestatin & $213.4 \pm 102.8$ & $178.2 \pm 100.2$ & $214.4 \pm 95.1$ & .537 & .448 & .201 \\
\hline
\end{tabular}

$T$-test for equality of means was used for comparison; Data are presented as mean $\pm S D$ or median (IQR), SD, standard deviation; yrs, years; $n$, number; UC, ulcerative colitis; VAS, visual analogue scale of appetite; BMI, body mass index; CRP, C-reactive protein; ESR, erythrocyte sedimentation rate; WBCs, White blood cells; CAI, colitis activity index; O/G ratio, obestatin/ghrelin ratio; P1, compared active disease vs healthy controls; P2, compared inactive disease vs healthy controls; P3, compared active disease vs inactive disease; P, Sig. (2-tailed); Significance at p-value $\leq 0.05$. 
Table 2: Spearman'rho correlations between different parameters in patients with Active Ulcerative Colitis

\begin{tabular}{|l|c|c|c|c|c|c|c|c|c|c|}
\hline & \multicolumn{2}{|c|}{ Obestatin } & \multicolumn{2}{c|}{ mRNA Obestatin } & \multicolumn{2}{c|}{ Ghrelin } & \multicolumn{2}{c|}{ mRNA ghrelin } & \multicolumn{2}{c|}{ O/G ratio } \\
\hline & $r$ & $p$ & $r$ & $p$ & $r$ & $p$ & $r$ & $p$ & $r$ & $p$ \\
\hline BMI & .238 & .169 & .256 & .137 & $-.285^{* *}$ & .003 & $-.158^{* *}$ & .012 & $.327^{* *}$ & .001 \\
\hline CRP & -.225 & .194 & $-.432^{* *}$ & .010 & $.841^{* *}$ & .000 & $.695^{* *}$ & .000 & $-.724^{* *}$ & .000 \\
\hline ESR & -.343 & .168 & $-.247^{* *}$ & .009 & $.541^{* *}$ & .000 & $.537^{* *}$ & .000 & $-.804^{* *}$ & .000 \\
\hline Inflammation score & -.032 & .857 & -.050 & .775 & $.389^{* *}$ & .021 & $.619^{* *}$ & .000 & $-.39-^{*}$ & .019 \\
\hline Endoscopic score & -.097 & .580 & -.028 & .874 & $.392^{* *}$ & .020 & $.502^{* *}$ & .002 & $-.41-^{*}$ & .012 \\
\hline CAI & .062 & .724 & -.079 & .653 & $.765^{* *}$ & .000 & $.837^{* *}$ & .000 & $-.535^{* *}$ & .001 \\
\hline Serum obestatin & 1.000 & & $.668^{* * *}$ & .000 & -.013 & .940 & -.052 & .766 & $.714^{* *}$ & .000 \\
\hline Serum ghrelin & -.013 & .940 & -.264 & .125 & 1.000 & & $.733^{* *}$ & .000 & $-.651^{* * *}$ & .000 \\
\hline O/G ratio & $.714^{* * *}$ & .000 & $.636^{* *}$ & .000 & $-.651-^{* *}$ & .000 & $-.580-^{* *}$ & .000 & 1.000 & \\
\hline mRNA ghrelin & -.052 & .766 & -.131 & .452 & $.733^{* *}$ & .000 & 1.000 & & $-.580-^{* *}$ & .000 \\
\hline mRNA obestatin & $.668^{* * *}$ & .000 & 1.000 & & -.264 & .125 & -.131 & .452 & $.636^{* *}$ & .000 \\
\hline
\end{tabular}

*.Correlation is significant at the 0.05 level (2-tailed); **. Correlation is significant at the 0.01 level (2-tailed); $r$, Correlation Coefficient; $P$, Sig.(2-tailed); BMI, body mass index; CRP, C-reactive protein; ESR, erythrocyte sedimentation rate; CAI, colitis activity index; O/G ratio, obestatin/ghrelin ratio; Significance at p-value $\leq 0.05$.

Of interest, the correlations between different parameters in patients with active UC were demonstrated in Table 2. It is shown that serum ghrelin level was positively and significantly correlated with CRP ( $r=0.841)$, ESR $(r=0.541)$, inflammation scores $(r=0.389)$, endoscopic scores $(r=0.392)$ and CAI of Rachmilewitz $(\mathrm{r}=0.765)$, and mucosal mRNA expression of ghrelin $(\mathrm{r}=0.733)$, $(\mathrm{p}<0.05$ for all). Moreover, it had a significant negative correlation with BMI ( $\mathrm{r}=-0.258, \mathrm{p}=0.003)$ and obestatin/ghrelin ratio $(\mathrm{r}=-$ $0.651, \mathrm{p}<0.0001)$. Although serum ghrelin level is negatively correlated with serum obestatin level, it is not statistically significant. It is demonstrated that obestatin/ghrelin ratio showed a significantly positive correlation with BMI $(\mathrm{r}=0.327, \mathrm{p}=0.001)$ and significantly negative correlations with CRP ( $\mathrm{r}=-0.724)$, ESR ( $\mathrm{r}=-$ $0.804)$, inflammation scores $(r=-0.394)$, endoscopic scores $(r=-$ 0.418 ) and CAI of Rachmilewitz ( $\mathrm{r}=-0.535)$, and mucosal mRNA expression of ghrelin $(r=-0.580)(p<0.05$ for all). Serum obestatin level showed no significant correlations except for a significantly positive correlation with obestatin/ghrelin ratio $(\mathrm{r}=0.714$, $\mathrm{p}<0.0001)$ and mucosal mRNA expression of obestatin $(\mathrm{r}=0.668$, $\mathrm{p}<0.0001)$. In this study, BMI showed significant negative correlations with CRP, ESR, inflammation score, endoscopic score and CAI (data not shown).

Serum ghrelin and obestatin levels and their mucosal mRNA expression were demonstrated in relation to disease location in Table 3. Active UC (40 patients) was left colic in 18 patients (45\%), right colic in 11 patients $(27.5 \%)$, pancolic in 7 patients $(17.5 \%)$, and sigmoid or rectum in 4 patients $(10 \%)$. Inactive UC (30 patients) was left colic in 12 patients $(40 \%)$, right colic in 11 patients $(36.7 \%)$, pancolic in 5 patients $(16.7 \%)$, sigmoid in 1 patient $(3.3 \%)$, and rectum in 1 patient (3.3\%). In patients with UC, this study didn't find any significant relationship between disease location and serum ghrelin, obestatin levels, obestatin/ghrelin ratio, and their colonic mucosal mRNA expression (ANOVA; $\mathrm{p}>0.05$ ).

Table 3: Serum levels and mRNA expression of Ghrelin and Obestatin in relation to disease location in Ulcerative Colitis

\begin{tabular}{|l|c|c|c|c|c|}
\hline & Left colic (30) & Right colic (22) & Pancolic (12) & Others (6) & ANOVA \\
\hline Number (n; Active/Inactive) & $30 ; 18 / 12$ & $22 ; 11 / 11$ & $12 ; 7 / 5$ & $6 ; 4 / 2$ & - \\
\hline Endoscopic Score & $6.12 \pm 2.6$ & $5.8 \pm 3.6$ & $6.3 \pm 3.6$ & $7.3 \pm 4.6$ & 0.870 \\
\hline Inflammation Score & $2 \pm 0.89$ & $1.8 \pm 1.1$ & $1.4 \pm 1.1$ & $2 \pm 1.4$ & 0.457 \\
\hline Colitis Activity Index & $6.88 \pm 2.1$ & $6.6 \pm 2.4$ & $6.6 \pm 2.7$ & $7.8 \pm 2.2$ & 0.821 \\
\hline Serum ghrelin (pg/mL) & $1177.3 \pm 402.5$ & $1147.5 \pm 489.5$ & $1048.1 \pm 335.1$ & $1219 \pm 525.8$ & 0.858 \\
\hline mRNA ghrelin & $780 \pm 226.8$ & $714.5 \pm 277.5$ & $645.7 \pm 207.5$ & $736 \pm 175.2$ & 0.491 \\
\hline Serum obestatin (pg/mL) & $364.5 \pm 91.5$ & $361.1 \pm 77.15$ & $377.4 \pm 94.3$ & $357 \pm 86.4$ & 0.964 \\
\hline mRNA obestatin & $179.9 \pm 102$ & $180.6 \pm 75.4$ & $174.5 \pm 97.7$ & $154.8 \pm 115.5$ & 0.058 \\
\hline Obestatin/ghrelin Ratio & $0.35 \pm 0.17$ & $0.39 \pm 0.21$ & $0.4 \pm 0.16$ & $0.32 \pm 0.11$ & 0.815 \\
\hline
\end{tabular}

Data are presented as mean $\pm S D, S D$, standard deviation; $S D$, standard deviation; $n$, number; ANOVA, analysis of variance; Significance at $p$ value $\leq 0.05$.

Table 4: Diagnostic accuracy of serum levels and mRNA expression of Ghrelin, Obestatin/Ghrelin ratio, and endoscopic score in patients with active Ulcerative Colitis

\begin{tabular}{|l|c|c|c|c|c|c|c|c|c|c|}
\hline & $\begin{array}{c}\text { Cutoff } \\
\text { value }\end{array}$ & $\begin{array}{c}\text { Sensitivity } \\
(\%)\end{array}$ & $\begin{array}{c}\text { Specificity } \\
(\%)\end{array}$ & PLR & NLR & $\begin{array}{c}\text { PPV } \\
(\%)\end{array}$ & $\begin{array}{c}\text { NPV } \\
(\%)\end{array}$ & $\begin{array}{c}\text { Accuracy } \\
(\%)\end{array}$ & $\begin{array}{c}\text { AUC } \\
\text { 95\% CI }\end{array}$ \\
\hline O/G Ratio & $\mathbf{0 . 3 5 9}$ & 95.45 & 93.31 & 12.41 & 0.051 & 95.34 & 91.21 & 94.29 & 0.845 & $0.653-0.989$ \\
\hline S. Ghrelin & 1238 & 91.3 & 76.92 & 3.96 & 0.11 & 87.5 & 83.33 & 86.11 & 0.701 & $0.601-0.928$ \\
\hline mRNA Ghrelin & 497 & 92.31 & 73.33 & 3.46 & 0.1 & 85.71 & 84.62 & 85.37 & 0.697 & $0.591-0.893$ \\
\hline Endoscopic score & 4 & 86.67 & 72.22 & 3.12 & 0.18 & 83.87 & 76.47 & 81.25 & 0.671 & $0.614-0.871$ \\
\hline CAI & 6 & 85.71 & 68.75 & 2.74 & 0.21 & 82.76 & 73.33 & 79.55 & 0.653 & $0.552-0.812$ \\
\hline
\end{tabular}

O/G ratio, obestatin/ghrelin ratio; CAI, colitis activity index; PLR, positive likelihood ratio; NLR, negative likelihood ratio; PPV, Positive predictive value; NPV, Negative predictive value; AUC, Area under the curve; 95\% CI, 95\% confidence interval. 
The diagnostic accuracy of serum levels and mucosal mRNA expression of ghrelin, obestatin/ghrelin ratio, and endoscopic score in patients with active UC were shown in Table 4. Obestatin/ghrelin ratio had the best sensitivity (95.45\%), specificity (93.31\%), positive predictive value (PPV; 95.34\%), negative predictive value (NPV; 91.34\%) and diagnostic accuracy (94.29\%). Receiver Operating Characteristics (ROC) curve for obestatin/ghrelin Ratio in patients with active UC was demonstrated in Figure 3. The area under the curve (AUC) and 95\%confidence interval (95\% CI) were 0.845(0.653-0.989) and the optimal cutoff value was 0.359 . Also, serum ghrelin and mucosal mRNA expression of ghrelin had good sensitivity (91.3\%, 92.3\%), PPV $(87.5 \%, 85.7 \%)$, NPV $(83.3 \%, 84.62 \%)$ and diagnostic accuracy $(86.1 \%, 85.37 \%)$ but lower specificity $(76.92 \%, 73.3 \%)$. ROC curve for Serum ghrelin and mucosal mRNA expression of ghrelin in patients with active UC was shown in Figure 4. The AUC (95\% CI) were 0.701(0.601-0.928) and 0.697 (0.591-0.893) respectively and cutoff values were $1238 \mathrm{pg} / \mathrm{mL}$ and $497 \mathrm{pg} / \mathrm{mL}$ respectively.

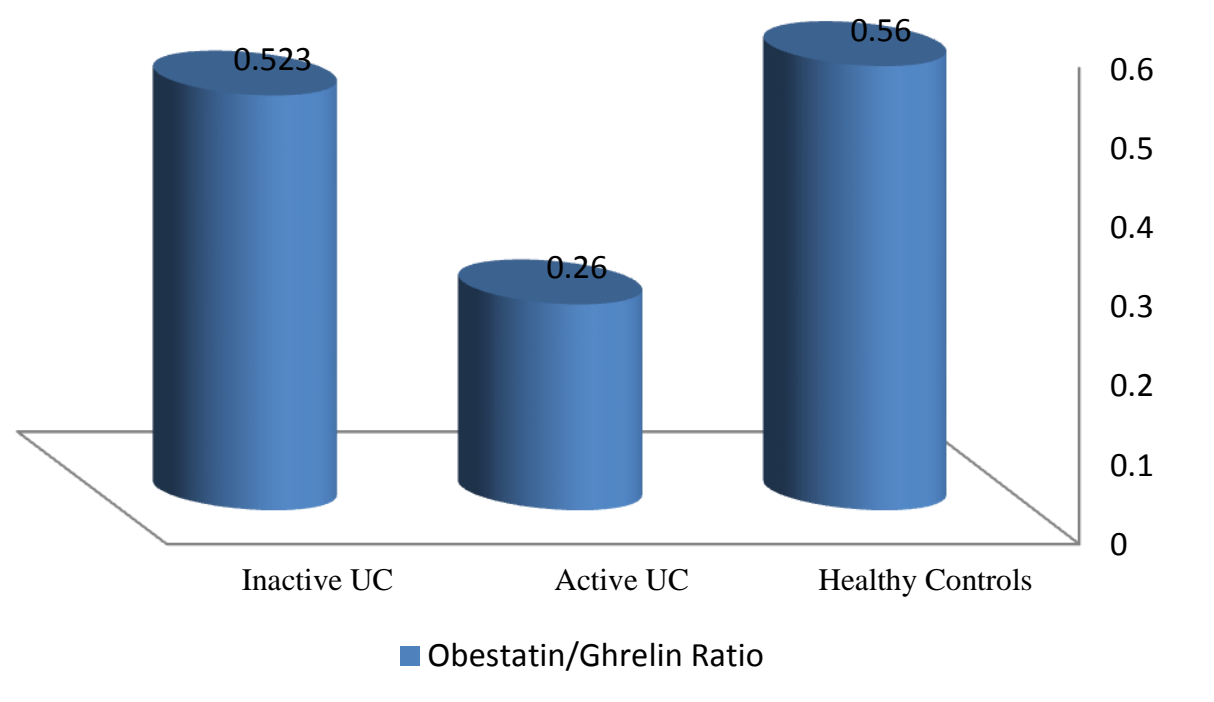

Figure 1: Mean Values of Obestatin/Ghrelin Ratio in Ulcerative Colitis (UC) Patients and Healthy Controls

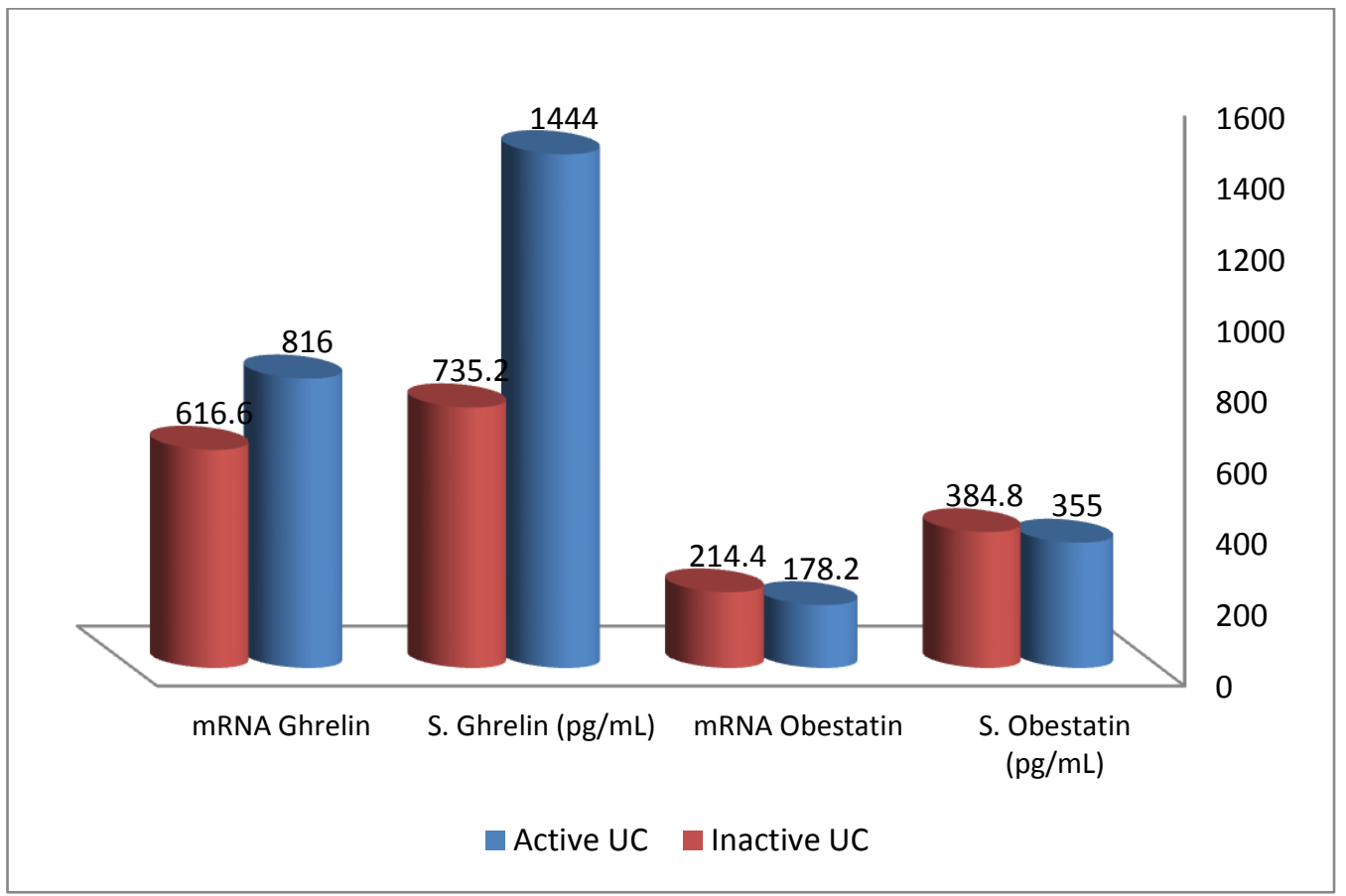

Figure 2: Mean Serum Values and mRNA expression of Ghrelin and Obestatin according to disease activity in Ulcerative colitis (UC) patients 


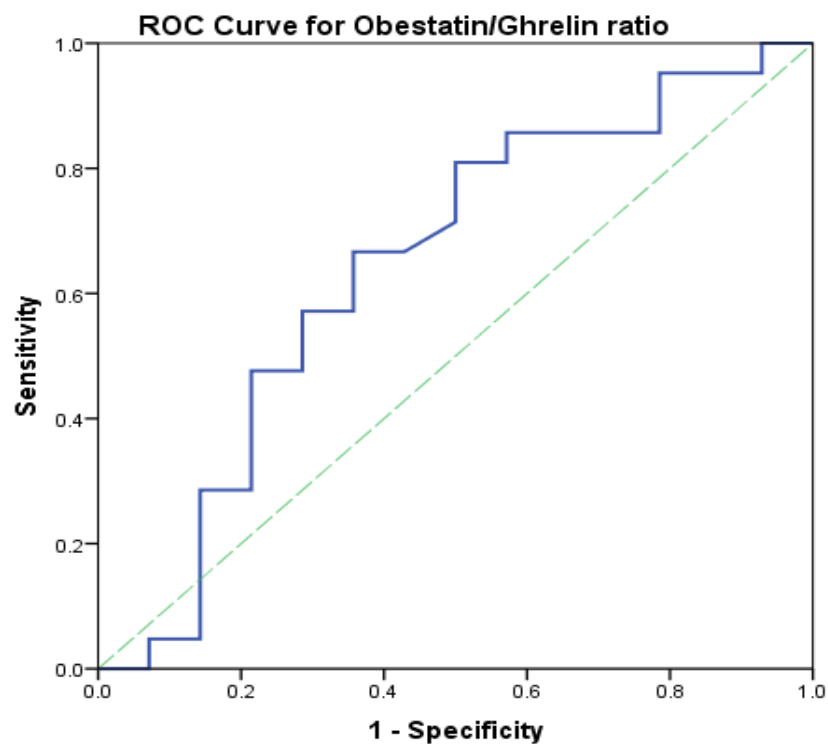

Diagonal segments are produced by ties.

Figure 3: Receiver Operating Characteristics (ROC) Curve for Obestatin/ Ghrelin Ratio in Patients with Active Ulcerative Colitis

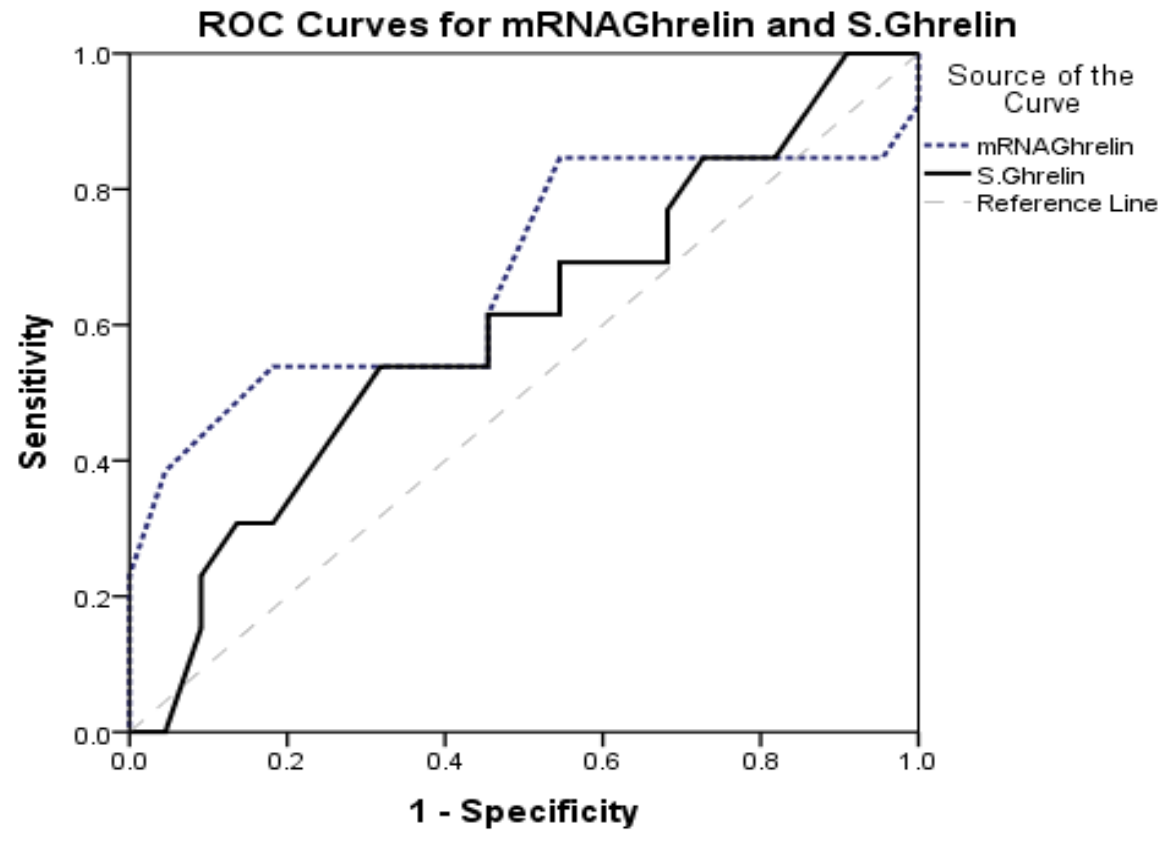

Diagonal segments are produced by ties.

Figure 4: Receiver Operating Characteristics Curves for Serum Ghrelin, mRNA expression of Ghrelin, in Patients with Active Ulcerative Colitis

\section{Discussion}

Ghrelin is anabolic appetite-regulatory hormone (short-term orexigen), expressed in and secreted by enteroendocrine cells located mainly in gastric mucosa. Only the active acylated (octanoylated) form of ghrelin has various endocrine and nonendocrine effects, plays central as well as peripheral roles in energy metabolism. Ghrelin has anti-inflammatory and immunomodulatory effects decreasing the circulating cytokines and promotes adipogenesis regulating somatic and adipose tissue growth. ${ }^{[7-10]}$ The balance of immunomodulatory, anti-inflammatory and proinflammatory factors determines the clinical course of IBD.

The present study investigated serum levels and colonic mucosal mRNA expression of ghrelin, obestatin, and obestatin/ghrelin ratio in Egyptian patients with UC and assessed their predictive values for UC disease activity and severity. This study demonstrated that serum ghrelin levels and colonic mucosal mRNA expression of ghrelin were significantly higher in patients with active UC than patients in remission and healthy controls $(p<0.0001)$. Contrary, serum obestatin level and its mucosal mRNA expression were lower in patients with active UC than patients in remission and healthy subjects but the differences were not statistically significant $(p>0.05)$. Consequently, obestatin/ghrelin ratio was significantly lower in patients with active UC $(0.26 \pm 0.08)$ than patients in remission $(0.523 \pm 0.16 ; \mathrm{p}<0.0001)$. Moreover, obestatin/ghrelin ratio was negatively and significantly correlated with the inflammation and endoscopic scores, colitis activity index of Rachmilewitz, serum ghrelin level and its mucosal mRNA expression $(\mathrm{p}<0.05)$. In addition, serum levels of ghrelin, obestatin, and their colonic mucosal mRNA expression didn't differ significantly according to UC disease location. 
The attenuation of the mRNA expression for ghrelin and the consequent reduction of ghrelin production in the gastric mucosa may account for the decrease in the serum ghrelin levels in patients with chronic gastritis. ${ }^{[12]}$ In patients with celiac disease, ghrelin levels were increased irrespective to the severity of duodenal inflammation. ${ }^{[13]}$ and reduced after treatment by gluten-free diet. ${ }^{[14]}$ In a rat-experimental study, exogenous administration of ghrelin (daily dose of $20 \mu \mathrm{g} / \mathrm{kg}$ i.p.) significantly ameliorated colitis and accelerated its healing, and associated with up-regulation of inducible nitric oxide synthetase (iNOS) mRNA expression in the colonic mucosa. $^{[22]}$

Lower plasma ghrelin levels were also reported in elderly patients with functional dyspepsia and intestinal metaplasia than those without intestinal metaplasia. ${ }^{[23]}$ In a study by Wang and his colleagues, serum ghrelin, but not obestatin, significantly decreased in early stages of acute pancreatitis and demonstrated to be a potential predictor of acute pancreatitis severity. However, several limitations were noted in their study. ${ }^{[24]}$

Nishi et al. demonstrated that there is no significant influence of inactive Crohn's disease on plasma ghrelin level. ${ }^{[25]}$ Hosomi et al. stated that colonic mucosal mRNA ghrelin expression was higher in patients with IBD than healthy subjects. ${ }^{[26]}$ Another study demonstrated higher serum ghrelin levels in patients with active IBD than those with inactive IBD, a significant negative correlation of obestatin/ghrelin ratio with the disease activity and a cutoff value for obestatin/ghrelin ratio $<1 .{ }^{[27]}$ Similar results were obtained in this study; higher serum ghrelin level in patients with active UC than patients with disease in remission and healthy controls which significantly and positively correlated with the disease activity. Moreover, this study demonstrated higher colonic mucosal ghrelin mRNA expression in active UC than inactive UC that significantly and positively correlated with the disease activity. Interestingly, the cutoff value in our study was lower than that obtained by previous studies (obestatin/ghrelin ratio $<0.359$ ).

Consistent with the results obtained in this study, Jung and his colleagues demonstrated increased serum ghrelin levels and colonic mucosal overexpression of ghrelin mRNA. They reported a low obestatin/ghrelin ratio in active UC with a cutoff value of obestatin/ghrelin ratio at $0.5 .{ }^{[28]}$ However, their study had several limitations, such as it was a retrospective study, with a small number of patients and no healthy control group. Contrary, a relatively large number of patients along with a healthy control group were enrolled in our study. Therefore, the relations between disease activity and serum ghrelin level, colonic mucosal mRNA ghrelin expression, and obestatin/ghrelin ratio were better identified in the present study. Unfortunately, this study was also a retrospective study and the relationship between ghrelin and other adipocytokines were not investigated.

Bowel inflammation is critically dependant on the efficient recruitment and activation of macrophages, with appropriate activation of nuclear factor NF- $\kappa \beta$, a transcription factor which plays a pivotal role in activation of proinflammatory cytokines $(\mathrm{TNF}-\alpha)$. It was demonstrated that activation of NF- $\kappa \beta$ and the consequent expression of TNF- $\alpha$ were significantly inhibited by exogenous ghrelin administration thus decreasing the bowel inflammation. ${ }^{[29]}$ Besides, the inflammatory mediators released in IBD could have a striking role in stimulation of ghrelin release from either gastrointestinal or extraintestinal tissues, such as visceral adipose tissue cells. ${ }^{[30]}$ Thus, it could be supposed that ghrelin exerts anti-inflammatory and protective actions in IBD. In this study, the greater inflammation in active UC was associated with higher ghrelin level and colonic mucosal overexpression of ghrelin mRNA leading to inhibition of proinflammatory cytokines and attenuation of bowel inflammations.

Collectively, these results suggested that both ghrelin and obestatin could play crucial and rational rules in pathogenesis, development, and even control of IBD. Indeed, it is possible to ascertain that ghrelin could ameliorate the inflammatory process in UC. However, the exact role of ghrelin in intestinal inflammation is not fully clarified, and the precise mechanism of increased serum and colonic mucosal ghrelin level in active IBD is not fully elucidated. However, the interplay between ghrelin and creeping fat is evident in patients with active $\mathrm{CD}$ (unlike UC). ${ }^{[30]}$ The creeping fat, progressive expansion of mesenteric white adipose tissue (WAT), and the immune cells could play pivotal roles in synthesizing adipokines which modulate intestinal inflammation. ${ }^{[31]}$

There is strong imaging evidence of submucosal fat deposition (fat halo sign) in patients with UC. This anatomic proximity of visceral WAT and the bowel favors the penetration of inflammatory reactions located in bowel wall to the surrounding visceral fat with consequent activation of visceral adipocytes and secretion of many adipocytokines, such as adeponectin, leptin, visfatin, resistin, ghrelin, and obestatin. These adipokines could modulate the immune system of gastrointestinal tract, magnify or alleviate the inflammatory reactions. In respect of this assumption, measuring the local mucosal and serum adipokines levels might serve as a disease activity index.

In all, the available literature on ghrelin, obestatin, and colitides support the conception that these hormones are key components of the biological pathways aroused during the onset of such disorders.

\section{Conclusion}

Despite the unclear mechanism of ghrelin up-regulation, the results of this study could imply that the increased serum and mucosal ghrelin levels are closely related to the inflammatory pathogenesis in UC. Obestatin/ghrelin ratio might be considered a credible noninvasive marker of disease activity in UC with significantly high diagnostic accuracy.

\section{Recommendation}

Ongoing research should explain the exact mechanisms underlying ghrelin effects and look for its potential implications for the diagnosis and therapy of IBD.

\section{Conflict of Interest}

The authors declared no conflicts of interest.

\section{Acknowledgment}

Authors thank Prof. Dr. Salah El-Gamal, Dr. Aya Mohammed Amin, and Ahmed Mohamed Amin for their support and help in writing this paper and statistical analyses.

\section{References}

[1] Goh J, O'Morain CA. Review article: nutrition and adult inflammatory bowel disease. Aliment Pharmacol Ther. 2003;17:307-320. 
[2] Bamias G, Nyce MR, De La, Cominelli F. New concepts in the pathophysiology of inflammatory bowel disease. Ann Intern Med. 2005;143:895-904.

[3] Ahualli J. The fat halo sign. Radiology. 2007;242:94546.

[4] Schäffler A, Schölmerich J, Büchler C. Mechanisms of disease: adipocytokines and visceral adipose tissue emerging role in intestinal and mesenteric diseases. Nat Clin Pract Gastroenterol Hepatol. 2005;2:103-11.

[5] DeBoer MD. Emergence of Ghrelin as a treatment for cachexia syndromes. Nutrition. 2008;24:806-814.

[6] Ariyasu H, Takaya K, Tagami T, Ogawa Y, Hosoda K, Akamizu T, et al., Stomach is a major source of circulating ghrelin, and feeding state determines plasma ghrelin-like immunoreactivity levels in humans. The Journal of Clinical Endocrinology and Metabolism. 2001;86(10):4753-58.

[7] Nakazato M, Murakami N, Date $\mathrm{Y}$, et al. A role for ghrelin in the central regulation of feeding. Nature. 2001;409:194-198.

[8] Dixit VD, Schaffer EM, Pyle RS, et al. ghrelin inhibits leptin- and activation-induced proinflammatory cytokine expression by human monocytes and $\mathrm{T}$ cells. J Clin Invest. 2004;114:57-66.

[9] Granado M, Priego T, Martin AI, Villanua MA, LopezCalderon A. Anti-inflammatory effect of the Ghrelin agonist growth hormone-releasing peptide-2 (GHRP-2) in arthritic rats. Am J Physiol Endocrinol Metab. 2005;288:E486-E492.

[10] Asakawa, A., A. Inui, T. Kaga, H. Yuzuriha and T. Nagata et al., 2001. Ghrelin is an appetite-stimulatory signal from stomach with structural resemblance to motilin. Gastroenterology, 120: 337-345.

[11] Cekic C, Arabul M, Alper E, Pakoz ZB, Saritas E, et al. Evaluation of the relationship between serum ghrelin, $\mathrm{C}$ reactive protein and interleukin- 6 levels , and disease activity in inflammatory bowel disease. Hepatogastroenterology. 2013;61:1196-200.

[12] Mohammed MA and Omar NM. Effect of H. pylori and its Eradication on Gastric Ghrelin Secretion. Trends in Medical Research. 2013;8:63-85.

[13] Peracchi M, Conte D, Terrani C, et al. Circulating Ghrelin levels in celiac patients. Am J Gastroenterol. 2003;98:2474-78.

[14] Capristo E, Farnetti S, Mingrone G, et al. Reduced plasma Ghrelin concentration in celiac disease after gluten-free diet treatment. Scand J Gastroenterol. 2005;40:430-436.

[15] Zhang JV, Ren PG, Avsian-Kretchmer O, et al. Obestatin, a peptide encoded by the Ghrelin gene, opposes ghrelin's effects on food intake. Science. 2005;310:996-99.

[16] Hwangbo Y, Kim HJ, Shim JJ, et al. Change of circulating leptin, adiponectin, resistin, and visfatin level after treatment of patients with active inflammatory bowel disease. Intest Res 2010;8:151-161.

[17] Kim HB, Lee ES, Oh SW, Kim YH and Lee DE, et al. Validity, reproducibility of visual analogue scales in assessment of appetite sensations. J. Korean Acad. Fam. Med. 2008;29:736-45.
[18] Rachmilewitz D. Coated mesalazine (5-aminosalicylic acid) versus sulphasalazine in the treatment of active ulcerative colitis: A randomised trial. BMJ. 1989;298:8286.

[19] Samuel S, Bruining DH, Loftus EV Jr, Thia KT, Schroeder KW, Tremaine WJ, et al. Validation of the ulcerative colitis colonoscopic index of severity and its correlation with disease activity measures. Clin Gastroenterol Hepatol 2013;11: 49-54;e1.

[20] Travis SP, Schnell D, Krzeski P, Abreu MT, Altman DG, Colombel JF, et al. Reliability and initial validation of the Ulcerative Colitis Endoscopic Index of Severity. Gastroenterology 2013;145:987-95.

[21] Ponchel F, Toomes C, Bransfield K, Leong FT, Douglas SH, Field SL, et al. "Real-time PCR based on SYBRGreen I fluorescence: An alternative to the TaqMan assay for a relative quantification of gene rearrangements, gene amplifications and micro gene deletions" (w). BMC Biotechnol. 2003;3: 18.

[22] Konturek PC, Brzozowski T, Engel M, Burnat G, Gaca P, Konturek SJ. Ghrelin ameliorates colonic inflammation. Role of nitric oxide and sensory nerves. Acta physiologica Polonica. 2009 Jun 1;60(2):41.

[23] Kim SH, Kim JW, Byun J, Jeong JB, Kim BG, Lee KL. Plasma Ghrelin level and plasma ghrelin/obestatin ratio are related to intestinal metaplasia in elderly patients with functional dyspepsia. PLoS One. 2017;12:e0175231.

[24] Wang H, Qin M, Liang Z, Chang R, Fu H, Wei Y, Tang G. Serum ghrelin, but not obestatin, is a potential predictor of acute pancreatitis severity. Medicine (Baltimore) 2017 Sep;96(35):e7963. doi: 10.1097/MD.0000000000007963

[25] Nishi Y, Isomoto H, Ueno H, et al. Plasma leptin and Ghrelin concentrations in patients with Crohn's disease. World J Gastrenterol. 2005;11:7314-7317.

[26] Hosomi S, Oshitani N, Kamata N, et al. Phenotypical and functional study of Ghrelin and its receptor in the pathogenesis of Crohn's disease. Inflamm Bowel Dis. 2008;14:1205-1213.

[27] Alexandridis E, Zisimopoulos A, Liratzopoulos N, Katsos I, Manolas K, Kouklakis G. Obestatin/Ghrelin ratio: a new activity index in inflammatory bowel diseases. Inflamm Bowel Dis. 2009;15:1557-61.

[28] Jung JY, Jeong JB, Kim JW, Kim SH, Koh SJ, Kim BG, Lee KL. Circulating Ghrelin levels and obestatin/ghrelin ratio as a marker of activity in ulcerative colitis. Intest Res. 2015 Jan; 13(1):68-73.

[29] Dixit VD, Schaffer EM, Pyle RS, et al.Ghrelin inhibits leptin- and activation-induced proinflammatory cytokine expression by human monocytes and $\mathrm{T}$ cells.J Clin Invest 2004;114:57-66.

[30] Karmiris K, Koutroubakis I, Xidakis C, Polychronaki M, Voudouri T, Kouroumalis E. Circulating levels of leptin, adiponectin, resistin, and Ghrelin in inflammatory bowel disease. Inflamm Bowel Dis. 2006;12:100-105.

[31] Tiaka EK, Manolakis AC, Kapsoritakis AN, Potamianos SP. Unraveling the link between leptin, ghrelin and different types of colitis. Ann Gastroenterol. 2011;24(1):20-28. Review. 